\title{
Mean centering, multicollinearity, and moderators in multiple regression: The reconciliation redux
}

\author{
Dawn Iacobucci $^{1}$ - Matthew J. Schneider ${ }^{2}$ Deidre L. Popovich ${ }^{3}$. \\ Georgios A. Bakamitsos ${ }^{4}$
}

Published online: 31 October 2016

(C) Psychonomic Society, Inc. 2016

\begin{abstract}
In this article, we attempt to clarify our statements regarding the effects of mean centering. In a multiple regression with predictors $\mathrm{A}, \mathrm{B}$, and $\mathrm{A} \times \mathrm{B}$ (where $\mathrm{A} \times \mathrm{B}$ serves as an interaction term), mean centering $\mathrm{A}$ and $\mathrm{B}$ prior to computing the product term can clarify the regression coefficients (which is good) and the overall model fit $\mathrm{R}^{2}$ will remain undisturbed (which is also good).
\end{abstract}

Keywords Moderated regression $\cdot$ Mean center

Perhaps our article, "Mean Centering Helps Alleviate 'Micro' But Not "Macro" Multicollinearity" had not been clear. We shall strive to be clearer.

Irwin and McClelland (2001) is frequently cited in support of the idea that mean centering variables prior to computing interaction terms to reflect and test moderation effects is helpful in multiple regression. Echambadi and Hess (2007) says that that school of thought is mistaken; that mean centering does not affect the multiple regression.

Dawn Iacobucci

dawn.iacobucci@owen.vanderbilt.edu

1 Vanderbilt University, Nashville, TN, USA

2 Decision Sciences, Drexel University, Philadelphia, PA, USA

3 Marketing, Texas Tech University, Lubbock, TX, USA

4 Marketing, Stetson University, DeLand, FL, USA
In Iacobucci et al. (2016), we reconcile these two points of view (note also, thereby in essence we defend Irwin and McClelland, 2001). We show how Irwin and McClelland (2001) are correct when one focuses on micro effects such as regression coefficients and Echambadi and Hess (2007) are simultaneously correct when one focuses on macro effects such as the model fit $R^{2}$. (Whereas the orientation in Irwin and McClelland (2001) and Echambadi and Hess (2007) is "either-or," the philosophy in Iacobucci et al. (2016) is that of "both-and.")

McClelland et al. (2016) forward two themes. First, there is a presentation of ideas about mean centering as in Irwin and McClelland (2001), as well as Aiken and West (1991) and Jaccard et al. (1990). Second, there is a criticism of Iacobucci et al. (2016). For example, the abstract opens with, "Multicollinearity is irrelevant to the search for moderator variables, contrary to the implications of Iacobucci et al. 2016." That might be a worthwhile thought to pursue, but it is not an issue referred to in Iacobucci et al. (2016). Contrary to the opinions of McClelland et al. (2016), the article by Iacobucci et al. (2016) contained no errors. More generally, McClelland et al. (2016) is perplexing — given that Iacobucci et al. (2016) defended Irwin and McClelland (2001) from criticisms in Echambadi and Hess (2007), to negate Iacobucci et al. (2016) is perhaps indicative of changing one's mind about Irwin and McClelland (2001) toward agreement with Echambadi and Hess (2007), and modifications are certainly legitimate in the path of scientific progress.

Whatever the concerns of McClelland et al. (2016), let us try to present our message more clearly. In a multiple regression with predictors $\mathrm{A}, \mathrm{B}$, and $\mathrm{A} \times \mathrm{B}$, mean centering $\mathrm{A}$ and $\mathrm{B}$ prior to computing the product term $\mathrm{A} \times \mathrm{B}$ (to serve as an interaction term) can clarify the regression coefficients. Doing 
so tends to reduce the correlations $\mathrm{r}(\mathrm{A}, \mathrm{A} \times \mathrm{B})$ and $\mathrm{r}(\mathrm{B}, \mathrm{A} \times \mathrm{B})$. We showed that the raw regression coefficient for the $\mathrm{A} \times \mathrm{B}$ term will not be affected (also see Disatnik and Sivan, 2016, on this point), ${ }^{1}$ and this term may well be of primary focus for many researchers, yet other researchers may also care about the status of the main effects for A and B as well, and these regression coefficients will be clarified. In addition, the mean centering transformation will leave the overall model fit $\mathrm{R}^{2}$ undisturbed. Thus our message is simply: yes, mean centering can help clarify regression coefficients (that is good) and it will not alter the overall $\mathrm{R}^{2}$ (that is also good).

Researchers do not have to mean center their variables prior to computing product terms - we are not (and none of us should be) in the business of dictating research processes. However, the message in Iacobucci et al. (2016) is that doing so can help (per Irwin and McClelland, 2001) and it will not hurt (per Echambadi and Hess, 2007).

Perhaps this recapitulation will strike readers more clearly. We merely echo the points of our reconciliatory paper (Iacobucci et al., 2016).

\section{References}

Aiken, L. S., \& West, S. G. (1991). Multiple regression: Testing and interpreting interactions. Newbury Park, CA: Sage Publications.

Disatnik, D., \& Sivan, L. (2016). The multicollinearity illusion in moderated regression analysis. Marketing Letters, 27, 403-408.

Echambadi, R., \& Hess, J. D. (2007). Mean centering does not alleviate collinearity problems in moderated multiple regression models. Marketing Science, 26(3), 438-445.

Iacobucci, D., Schneider, M. J. Popovich, D. L., and Bakamitsos, G. A. (2016), Mean centering helps alleviate 'micro' but not 'macro" multicollinearity. Behavior Research Methods, December, forthcoming.

Irwin, J. R., \& McClelland, G. H. (2001). Misleading heuristics and moderated multiple regression models. Journal of Marketing Research, 38, 100-109.

Jaccard, J. R., Turrisi, R., \& Wan, C. K. (1990). Interaction effects in multiple regression. Newbury Park, CA: Sage Publications.

McClelland, G. H., Irwin, J. R., Disatnik, D., and Sivan, L. (2016). Multicollinearity is a red herring in the search for moderator variables: A guide to interpreting moderated multiple regression models and a critique of Iacobucci, Schneider, Popovich, and Bakamitsos (2016). Behavior Research Methods, December, forthcoming.

\footnotetext{
${ }^{1}$ Their result is also obtained on raw regression weights (b weights), not standardized regression weights, even though they use the notation of $\beta$ 's, which should be clear in part because they include an intercept $\beta_{0}$ term in their model, and for standardized regression coefficients, this term of course would be zero.
} 